\title{
Aproximación a la amenaza GAO - GDO \\ según su financiación ilícita ${ }^{1}$
}

FERNANDO ChAVARRo MIRANDA ${ }^{2, *}$
VlaDIMIR OSORIO $^{3, * *}$

\section{Resumen}

Este artículo trata sobre los grupos organizados al margen de la ley -GAO y GDO- y el crecimiento estratégico que tienen con respecto a temas de seguridad y el aumento delictivo de su accionar, con la ayuda del aumento de su capital, a través de las fuentes de financiamiento que estos utilizan. Con el fin de demostrar esa afirmación se realizó una búsqueda de cincuenta artículos académicos y no académicos, en bases de datos especializadas a las que tienen acceso la Universidad Militar Nueva Granada y la Universidad del Rosario.

Se desarrollan, entonces, para relacionar conceptos y variables, elementos tales como: narcotráfico, lavado de activos, empresa ilegal, tráfico de personas, corrupción, minera ilegal y tráfico de flora y fauna. La principal conclusión es que existe una relación entre la relevancia de las actividades de lavado de activos con la supervivencia, perpetuación y crecimiento de estos grupos por medio de la capacidad adquisitiva.

Palabras claves: GAO, GDO, capacidad adquisitiva, elementos de financiación, lavado de activos.

Clasificación JEL: K42, K14, H56, G15, G38.
${ }^{1}$ Artículo de investigación de la Línea Democracia, Inteligencia y Estado de Derecho.

${ }^{2} \mathrm{PhD}$. Businees Administration,

Maastrich University. Doctor en Administración Estratégica, Pontificia Universidad Católica de Perú. Magíster en Economía Universidad de Los Andes.

Especialista en Investigación, Universidad Santo Tomás Especialista en Finanzas, Universidad del Rosario. Economista, Universidad de La Salle. Asesor de la Escuela de Inteligencia y Contrainteligencia, Brigadier General Ricardo Charry Solano, Colombia; Investigador Universidad Juan de Castellanos. orcid: https://orcid.org/0000 0003-4711-7196

*fernando.chavarro@yahoo.es.

${ }^{3}$ Estudiante de Maestría en Inteligencia y Contrainteligencia, ESICI; Especialista en Negocios

Internacionales; Profesional en Negocios Internacionales; Profesor de la Escuela de Inteligencia y Contrainteligencia, Brigadier General Ricardo Charry Solano, Colombia. *vsaza35@gmail.com

Fecha de recepción: 8 de noviembre de 2017

Fecha de aceptación: 6 de junio de 2018

Para citar este artículo: Chavarro, F. y Osorio, V. (2018). Aproximación a la amenaza GAO - GDO según su financiación ilícita. Perspectivas en inteligencia, 10(19): 245-277. 


\section{Abstract}

This paper is about the Organized Groups out of the law (GAO-GDO) and the strategic growing that it had been as far of security and the criminal increase of their behaviour, with the help of their increasing capital through the differents sources of financing. In order to prove this affirmation we made a research of 50 papers and articles in databases of the University Militar Nueva Granada and University del Rosario. It developed elements of financing as drug trafficking, money laundering, illegal Enterprise, human trafficking, corruption, illegal mining, flora and fauna trafficking. The main conclusion is the existing relations among the relevance of the money laundering with the survival, perpetuation and growing of these groups through their purchasing capacity.

Keywords: GAO, GADO, purchasing capacity, financial elements, money laundering.

JEL classification: K42, K14, H56, G15, G38. 


\section{Introducción}

Los Grupos Armados Organizados (GAO) y los Grupos Delincuenciales Organizados (GDO), son los nuevos actores criminales que, mediante la transformación del accionar de actores estatales, trajo consigo fenómenos como el terrorismo, el tráfico de estupefacientes, el tráfico de personas y el tráfico de material nuclear, estableciendo así implicaciones a la seguridad estatal y provocando un cambio paradigmático en la seguridad nacional.

Estas amenazas se diferencian de las tradicionales puesto que poseen una naturaleza no militar y su alcance es transnacional, lo que sugiere nuevos retos para los Estados por el uso de tácticas para traspasar fronteras estatales, las que se contraponen a las formas tradicionales de librar las guerras y a las políticas de seguridad nacional, lo que significa un giro en la forma en la que se concibe la seguridad internacional (Zúñiga, 2016). En ese sentido, se puede observar la evolución y crecimiento que han tenido estas organizaciones mediante el desarrollo de rutas para el transporte de los diferentes métodos de financiación, imponiendo también una nueva forma de crimen, en la cual el Estado no tiene control sobre este.

La existencia de otras condiciones políticas, sociales, económicas y culturales facilita la perpetuación y la supervivencia de estos grupos. Así mismo, las estructuras sociopolíticas y económicas ligadas, sobre todo al narcotráfico y a la fragilidad de las instituciones y la democracia locales, que se convirtieron en oportunidad para el auge y la expansión de las autodefensas ilegales, también han contribuido a la aparición de las Bacrim, así como a alimentarlas con los insumos materiales e institucionales de los que se sostuvieron los paramilitares y con los reductos -humanos- de estas organizaciones que no fueron absorbidos por el proceso de Justicia y Paz (Torrijos, 2010). En efecto, organizaciones como las FARC, el ELN y hasta las Bandas Criminales Emergentes-Bacrim, antes ligadas a las fuerzas de autodefensa y hoy tan asociadas al narcotráfico, se caracterizan por su enorme versatilidad y resiliencia. No por esto, sin embargo, Colombia ha renunciado a la posibilidad y el desafío estratégico de derrotarlas de forma convencional (Torrijos, 2010).

Así mismo, la delincuencia organizada evolucionó en sus métodos y objetivos, de acuerdo con los cambios del entorno; muchos grupos activaron mecanismos tecnológicos en sus actos y/o desviaron su atención a otro tipo de delitos. También, las medidas de prevención y autoprotección de las autoridades y los sectores afectados modificaron su modus operandi, como es el caso del hurto de automotores o de celulares, que pasaron de la comercialización interna al 
envío hacia redes internacionales (Giraldo, Ocampo, Tuta, Gallego \& López, 2015), fomentando los lazos y diversificando sus elementos de financiación.

Para entender el estudio de los GAO y GDO se debe tener en cuenta que en la mayoría de las investigaciones o artículos se definen como grupos criminales derivados del crimen transnacional. Es por esto que estos grupos, son entendidos bajo el concepto de crimen organizado transnacional. Hamann (2008), lo entiende como:

Actores no estatales que están desafiando la legitimidad yla autoridad del Estado, siendo la principal amenaza para la seguridad internacional, representada por el crimen organizado. Los avances en tecnologías de la información y las comunicaciones en el contexto de la globalización han facilitado sus operaciones, permitiendo que estas organizaciones se transformaran, pasando de organizaciones jerárquicas a organizaciones estructuradas como "redes sociales". Estas "redes" criminales han demostrado ser flexibles, dinámicas, elusivas a la acción de las autoridades y adaptables a los cambios, y se han convertido en un gran reto para el Estado en su lucha contra el crimen organizado transnacional (s.p.).

Además, estos grupos son entendidos como empresas por lo que la teoría jerarquizada es aplicable en tanto que Holmes \& Kent (1991) proponen una teoría de la jerarquía financiera restringida para las pequeñas y medianas empresas, ya que sostienen que emitir capital accionario externo no es una opción para este tipo de empresas, puesto que puede no estar disponible, no interesar al empresario por el temor a perder control de su empresa. En consecuencia, estas empresas son menos rentables, dependen en mayor grado del acceso a la deuda y puente enfrentar dificultades en el acceso a crédito a largo plazo por las mayores asimetrías en la información, debido a que los dadores de fondos son conscientes de este efecto de selección adversa.

La implicación teórica está ligada a la aplicación de la teoría de la jerarquía financiera restringida a los grupos criminales, dado que se asume que estos son empresas pequeñas o medianas que prefieren el financiamiento interno. De igual manera, se trabaja de esta manera porque permite una comprensión más integral de los elementos de financiación de estos grupos, lo que a nivel práctico podría generar políticas de contención.

Lo anterior, motivado por la manera en la que se desarrollaron y como han diversificado los distintos mercados criminales en los que operan, como el tráfico de personas y, posteriormente, expandirse hacia el tráfico de drogas, 
utilizando las estructuras generadas en el primer mercado (J.J., 2015). Teniendo en cuenta lo anterior y la actual transnacionalización de estos grupos hace que sea muy difícil evaluarlos en su totalidad, ya que muchas de las actividades y fenómenos criminales que realiza un grupo se ejecutan en distintos países de manera casi simultánea como elementos de financiación.

Hoy en día, la competencia tiene lugar entre las tradicionales familias de la delincuencia organizada que, de hecho, gobiernan las áreas remotas de los países en los que operan. Además del tráfico de cocaína, estos grupos están implicados en un amplio rango de actividades de delincuencia organizada y en la manipulación de políticos locales. Si disminuyen los flujos de cocaína, estos grupos buscarán ingresos en otras formas de delito del que se obtiene una ganancia material, como la extorsión, lo que podría aumentar los niveles de violencia (UNODC, 2012).

En este sentido, la delincuencia organizada es quizás el agente que más impacta en la seguridad de la ciudad, debido a su capacidad para dirigir recursos a objetivos específicos bajo un principio de asociación, donde las personas que la conforman poseen habilidades para infringir la ley, producto de su aprendizaje y trayectoria en el oficio del crimen (UNODC, 2012). Partiendo de esto, este artículo busca ahondar y demostrar la interconexión entre los diferentes elementos de financiación, lo que permite una mejor comprensión de este fenómeno.

\section{Metodología}

El artículo tiene enfoque cualitativo, porque tiene planteamientos más abiertos, además no se fundamenta en la estadística. Surge de la necesidad de los huecos de conocimiento en cuanto a la profundización y correlación de los elementos de financiación del crimen organizado. Para el desarrollo de la perspectiva teórica primero se realizó la revisión de literatura, seleccionando fuentes secundarias apoyadas en diferentes bases de datos académicas de la Universidad del Rosario y de la Universidad Militar Nueva Granada; así mismo, se recolectó información de Google Scholar. Para la elección de los artículos se realizó una lectura estratégica inicial del resumen ejecutivo, la introducción y las conclusiones; posteriormente, se leyó el texto completo y se extrajeron los aspectos más relevantes en cuanto al o a los elementos de financiación que el texto plantea. La recolección de datos se hizo a través de la estructuración de los mismos, organizando y transcribiéndolos (Sampieri, 2014). El diseño es de teoría fundamentada donde sus procedimientos fueron codificación de las categorías en primer lugar, de forma abierta y, en segundo lugar, axial, con el fin 
de dar cuenta de los vínculos entre las categorías, lo cual tendrá por resultado la generación de hipótesis, explicaciones y/o teorías.

\section{Elementos de financiación de los GAO y GDO}

Los elementos de financiación del crimen organizado aplicados a los Grupos Armados Organizados y a los Grupos Delictivos Organizados son el narcotráfico, el lavado de activos, la empresa ilegal, el tráfico de persona y migrantes, la corrupción, la minería ilegal, tráfico de flora y fauna y el tráfico de armas.

\subsection{Narcotráfico}

El tráfico de drogas sigue siendo la forma más lucrativa de negocio para los delincuentes, ya que tiene un valor anual estimado en 320.000 millones de dólares. En 2009, la Oficina de Naciones Unidas Contra la Droga y el Delito-UNODC calculó que el valor anual aproximado de los mercados mundiales de cocaína y opiáceos ascendía a 85.000 millones de dólares y 68.000 millones de dólares, respectivamente (UNODC, 2011). Es por esto que los grupos al margen de la ley observan la alta rentabilidad y, por ende, es una de las fuentes más utilizadas.

El crimen organizado internacional es una de las amenazas principales y comunes que enfrenta América Latina y el Caribe. Según la percepción de amenazas priorizadas por subregión de Rojas (2002), el narcotráfico encabeza la lista de amenazas prioritarias tanto para Mercosur, Países Andinos, Centroamérica y Caribe (figura 1). Dicha coincidencia involucra al narcotráfico como la primera problemática común. No obstante, aunque el crimen organizado esté como prioridad de amenaza del hemisferio, este se establece en un lugar importante si se tiene en cuenta que el narcotráfico es una de las expresiones más significativas del crimen organizado en la región debido a la rentabilidad que este representa (Betancourt, 2014).

Así pues, el narcotráfico es la principal actividad del crimen organizado y manifestación de criminalidad en América Latina. Todo el hemisferio ha sido inundado por las actividades y actores del narcotráfico. En la obra "Cooperación policial entre Colombia y Centroamérica y el Caribe: El Crimen Organizado y el accionar de Ameripol bajo el enfoque multidimensional de la Seguridad Hemisférica", se evidencia que el narcotráfico ha aumentado la criminalidad en América y ha generado corrupción, violencia y desestabilización política. Es una actividad ilícita que genera consecuencias más allá de su foco de acción (Betancourt, 2014). De esta manera, el crimen organizado transnacional no 
Pereepelones de amenazas priorizadas por subregiones

\begin{tabular}{|c|c|c|c|}
\hline Mercosur & Paises Andines & Centroamérica & Caribe \\
\hline Narcotráfico & Narcotrafico & Narcotráfico & Narcotráfico \\
\hline Terrorismo & Terrorismo & Terrorismo & Terrorismo \\
\hline Tráfico de armas & $\begin{array}{c}\text { Pobreza y carencias } \\
\text { sociales }\end{array}$ & $\begin{array}{l}\text { Medio ambiente y } \\
\text { desastres naturales }\end{array}$ & $\begin{array}{c}\text { Pobreza y carencias } \\
\text { sociales }\end{array}$ \\
\hline Crimen organizado & $\begin{array}{l}\text { Guerrillas y grupos } \\
\text { subversivos }\end{array}$ & Crimen organizado & $\begin{array}{l}\text { Medio ambiente y } \\
\text { desastres naturales }\end{array}$ \\
\hline $\begin{array}{l}\text { Medio ambiente y } \\
\text { desastres naturales }\end{array}$ & Tráfico de armas & $\begin{array}{c}\text { Pobreza y carencias } \\
\text { sociales }\end{array}$ & Trafico de armas \\
\hline $\begin{array}{c}\text { Pobreza y carencias } \\
\text { sociales }\end{array}$ & Crimen organizado & Tráfico de armas & Crimen organizado \\
\hline $\begin{array}{l}\text { Guerrilla y grupos } \\
\text { subversivos }\end{array}$ & $\begin{array}{l}\text { Medio ambiente y } \\
\text { desastres naturales }\end{array}$ & $\begin{array}{c}\text { Guerrilla y grupos } \\
\text { subversivos }\end{array}$ & \\
\hline
\end{tabular}

FIGURA 1. Amenazas por regiones

El gráfico da cuenta de la percepción de amenazas en las subregiones de América Latina en la que el narcotráfico es una constante en todas las subregiones.

sólo trafica drogas, sino que controla, corrompe y combate a las instituciones estatales y se extiende a la propagación de muchos otros ilícitos.

Enfatizando en América Latina, el tráfico de drogas es la principal manifestación de la criminalidad organizada. En esta región se produce el cien por ciento de la cocaína que se consume a nivel mundial y es a partir del tráfico de drogas que se potencian, directa o indirectamente, el comercio ilegal de armas pequeñas y livianas, la industria del secuestro, el contrabando, la corrupción y otros ilícitos (Bartolomé, 2006). Como se ha dicho, las acciones ilegales y la manera en la cual se financian estos grupos delictivos va coordinada y estructurada para que funcionen de tal manera que una subsista de la otra.

\subsubsection{La criminalidad en el asunto de las drogas}

Hay dos lados en los asuntos de las drogas: a) el lado técnico (mecánico) en el cual lidian con la producción, procesamiento, comercialización y operaciones de lavado de activos; y b) el lado criminal, en el que se lidia con los actores ilegales, sus actividades terroristas como el secuestro, la extorsión, el asesinato y el chantaje, y sus efectos en el Estado. La riqueza crece con las redes criminales, la relación usualmente se convierte en violenta a nivel nacional y se caracteriza por la confrontación usando las tácticas terroristas (Vibes, 2001).

Si bien en Colombia los grupos delincuenciales, y especialmente los grupos armados organizados, hacen parte de los dos asuntos de las drogas, es importante señalar que la relación entre ambos asuntos es muy estrecha. Esto se debe a que, si un mismo grupo hace uso del primero, generalmente tenderá a 
hacer uso de los demás componentes de la criminalidad dado que es igualmente rentable, además de que estos actos fomentan el terror en el territorio del cual ostentan el control, facilitando en este sentido la perpetuación de los ciclos tanto del lado técnico como del criminal.

Los grupos de crimen organizado en Colombia se transforman a medida que los ideales con los que inician las guerrillas se van perdiendo debido a la eliminación paulatina de los líderes cuyos propósitos estaban relacionados con la obtención del poder y no con ánimos de lucro. Las FARC y el ELN se benefician del comercio de drogas fomentando sus objetivos revolucionarios. Es importante resaltar que esa relación es nueva ya que originalmente los grupos insurgentes y el crimen organizado no tenían intereses en común, el único enemigo en común era el Estado. Actualmente, las guerrillas y los narcotraficantes están involucrados en actividades criminales combinadas, lo que les permiten tener acceso a otras fuentes de ingresos (Vibes, 2001).

Como la autora afirma que las guerrillas tiene principalmente dos intereses, por un lado político y, por el otro, económico, es por esto que la convergencia de intereses, particularmente de los lucrativos, ha llevado a que los propósitos revolucionarios de las guerrillas se pierdan, modificando así el carácter de las mismas y explicando, en cierta medida, los cambios en su accionar, puesto que el narcotráfico ha sido una gran fuente de financiación a partir de la eliminación de los grandes carteles de la droga, dado que estos grupos guerrilleros han ocupado los vacíos y han exponenciado los diferentes niveles del lado técnico y criminal. Lo anterior, con el fin de garantizar su supervivencia al incrementar las ganancias mediante las cuales tienen acceso a más armas, terreno y demás aspectos que producen la continuidad de sus fuentes de poder y, por lo tanto, de financiación, continuando con la perpetuación del crimen organizado a través del narcotráfico puesto que es la fuente de financiación por excelencia, en especial porque en cierta medida este fenómeno se ha normalizado en la sociedad.

Así como afirman Sousa \& Ferreira (2004), que el surgimiento y fortalecimiento del narcotráfico en las favelas cariocas se da como una forma histórica, cultural y simbólica local que es asimilada a una estructura de poder - así se entiende al crimen organizado- que está estructurada por un comercio ilícito de drogas en Río de Janeiro. Las favelas cuentan ya con las estructuras de poder necesarias para que el crimen organizado global opere. Esto puede ser perfectamente aplicado al caso colombiano en donde los grupos armados organizados en cierto grado se han interiorizado en la sociedad, además que estos cuentan con estructuras menos jerarquizadas, lo cual permite que se puedan crear los nexos con otros grupos extranjeros o incluso formar grupos transnacionales. 
Asípues, las organizaciones criminales han ganado relevancia, yhan desarrollado expresiones de criminalidad asociadas principalmente al narcotráfico, entre ellas la trata de personas. En este sentido, es considerado que el narcotráfico se ha constituido como la mayor amenaza a la seguridad pública, seguida por la trata de personas, lo que afecta esencialmente a los más jóvenes (Solis \& Rojas, 2008). En efecto, para mucha gente el "crimen organizado" está tan vinculado al narcotráfico que ambos fenómenos se entienden como sinónimos.

Teniendo en cuenta lo anterior, los grupos participan en las fases intermedias de la cadena del narcotráfico, como la compra de pasta base, la producción de clorhidrato, la custodia y embarque y el control del microtráfico de consumo interno. Mediante el control de estas fases, en las que se genera buena parte de las ganancias, estos grupos aseguran una fuente de financiación muy rentable y apenas equiparable, en apariencia, con los recursos generados por actividades como la minería ilegal o la micro extorsión.

Debido a este negocio, están en la capacidad no solo de financiar su componente armado y redes de apoyo, sino de definir sus estrategias de expansión y disputa territorial con el objetivo de controlar zonas de cultivo, corredores estratégicos para el procesamiento y la distribución, mercados internos y puntos de embarque hacia el exterior, así como de controlar e involucrar a la población que vive en las zonas en las que trabajan (Prieto, 2013).

Los antecesores de los grupos armados organizados y de los grupos delincuenciales organizados son las bandas criminales que surgen tras la desmovilización de los paramilitares o grupos de autodefensas. BojicicDzelilovic, Kostovicova, Escobar, \& Bjelica (2015), argumentan que el cambio analítico de los actores a las relaciones es necesario para entender cómo las estructuras de gobernanza enraizadas en el crimen organizado, y sus nexos con el conflicto, suponen un riesgo para la ayuda internacional en cuanto al cambio de elementos de financiación que sostiene a la sociedad.

A lo anterior se le puede agregar el hecho de que los oficiales de la autoridad regional de la tierra facilitaron el proceso de desplazamiento, por parte de las AUC en los 90's en Urabá, a las comunidades afrocolombianas de partes de sus territorios protegidos colectivos en la cuenca de los ríos Curvaradó y Jiguamiando con el fin de expandir las plantaciones del aceite de palma y asegurar el narcotráfico (Bojicic-Dzelilovic, Kostovicova, Escobar, \& Bjelica, 2015, 2015). La problemática de la implementación de alternativas para las comunidades que se han visto fuertemente golpeadas por el conflicto ha abierto una oportunidad para los grupos del crimen organizado, puesto que ha 
generado un atractivo en estos territorios, no solo para hacerse a los medios legales mediante el lavado del dinero del narcotráfico, sino para asegurar la continuidad del mismo.

Es importante resaltar que las ganancias obtenidas del narcotráfico representan un poder económico capaz de infiltrar las esferas estatales a través de la corrupción de funcionarios y empleados, así como la capacidad para financiar organizaciones civiles, políticas, candidaturas a alcaldías y demás elecciones públicas. También permite la conexión con otros delitos tales como el lavado de activos y el tráfico de armas (Clavería, 2011, p. 13). La conexión con otros delitos facilita el fortalecimiento y la perpetuación de los grupos armados organizados puesto que, generalmente, las rutas utilizadas para el narcotráfico son las mismas que se utilizan para el tráfico de armas y las ganancias de ambos permiten las diversas actividades de lavado de activos.

\subsection{Lavado de activos}

\subsubsection{Proceso del lavado de activos}

De acuerdo con Savona y De Feo (1997), el lavado de activos es un proceso de tres pasos que requiere, posicionamiento, estratificación e integración. El posicionamiento es una disposición física de dinero y movimientos de fondos de asociación directa con el crimen y ponerlo en el sistema financiero, esto envuelve también la complicidad del banco, la mezcla de fondos lícitos e ilícitos compra de dinero y el actual contrabando de paraísos fiscales. El disfrazar la estratificación involucra la creación de papeles falsos, la conversión de dinero en instrumentos monetarios y la conversión de activos tangibles obtenidos por la compra de dinero, este proceso es facilitado y aumentado por el uso de métodos electrónicos. La integración habilita el dinero criminal nuevamente con sus orígenes ocupacionales y geográficos escondidos de la vista (pp. 23-24).

El dinero generado por el narcotráfico, el tráfico de armas y el crimen financiero es de poca utilidad a menos de que ellos puedan disfrazarlo y convertirlo en fondos hábiles para invertirlos legítimamente en empresas. Es importante el nivel del problema y los problemas que causa por los métodos utilizados en los que la corrupción es muy utilizada, de igual manera, es relevante por las oportunidades de supervivencia y expansión que ofrece a los grupos de crimen organizado. "Si no tuvieran esta capacidad serían menos rentables y, por lo tanto, más vulnerables a los constantes cambios y restricciones que se le ponen a las otras fuentes y a las transacciones financieras" (Wright, 2006, 68). 
La lucha contra el lavado de activos ha sido constante y se han creado diferentes conferencias con el fin de mitigar las oportunidades existentes en los mercados financieros y en las industrias legales para legalizar el dinero ilegal. El principal objetivo de la conferencia Courmeyer de 1994, según Wright (2006), es hacer los mercados financieros transparentes, minimizando la circulación del dinero criminal y su influencia en las industrias legítimas.

De igual manera, se denomina al posicionamiento como inmersión, a la estratificación como "jabonada dura" y a la integración como "centrifugadora" (Wright, 2006, p. 69 -70). De igual manera, afirma que "las fronteras entre los negocios sucios y el lavado de activos están lejos de estar claras, no solamente los criminales están involucrados en estos procesos. Aparentemente, corporaciones legítimas también realizan lavado de activos" (Wright, 2006, 71). Este proceso de lavado de activos ha evolucionado mucho hasta la profesionalización del mismo, esto se debe a la progresiva separación entre las actividades criminales y las actividades de lavado de activos; más lavadores profesionales como contadores, abogados y banqueros privados; y proveer los servicios de lavado de activos a un gran rango de criminales y a más de una organización criminal.

\subsubsection{Factores del incremento}

Existen algunos factores del gran crecimiento de lavado de activos: a) el simple aumento de escala de las empresas ilícitas le facilita al crimen organizado estar en el negocio del dinero; b) la globalización de las comunicaciones y el comercio; y c) la tendencia hacia la falta de una regulación efectiva financiera en ciertas partes de la economía global Los factores se mezclan entre sí (Wright, 2006, 69).

Las oportunidades para que el crimen organizado dependa mucho de las formas exactas que tome la economía informal en los diferentes países y en lo social y cultural, transportar y vender drogas ilegales casi siempre está relacionado con el crimen organizado. Seddon muestra que los procesos de globalización han facilitado el comercio legal y las finanzas internacionales también han beneficiado al comercio ilegal como las drogas. "Por otro lado, en esferas muy diferentes, las estructuras de los mercados y el creciente carácter internacional de los actores en esos mercados puede permitir que las transacciones lícitas e ilícitas se entrelazan" (Ponsaers, Shapland, \& Williams, 2008, 647). La falta de regulación común a nivel internacional es un factor que fomenta el uso de las actividades de lavado de activos como un elemento de financiación para los grupos armados organizados, puesto que el proceso puede ser realizado en línea en países que no tienen procesos específicos en los que se determine el origen del dinero y, por lo tanto, son más laxos en dichos procesos creando grandes oportunidades para el lavado de activos. 
A su vez, Nelen (como se citó en Ponsaers, Shapland, \& Williams, 2008, p. 648), explora el potencial en el estado real de las transacciones fraudulentas o las actividades de lavado de activos, el afirma que la falta transparencia en particular en los mercados y su creciente carácter internacional se manifiestan como facilitador de la potencial incursión del crimen organizado puesto que no hay exigencias ni regulaciones que determinen la proveniencia del dinero.

Ponsaers, Shapland, \& Williams (2008), argumentan sobre las actividades de la economía formal y las de la economía informal que son espejos, con la frontera entre ellas moviéndose constantemente. Se ha visto que ellos están también conectados en sus métodos y estructuras de oportunidad, unidos a través de oportunidades comunes percibidas. Donde hay más transparencia sobre transacciones y estructuras y en donde las tradiciones culturales o históricas hacen más "normal" o "aceptado" las actividades de economía informal parecen ser más hábiles de penetrar estas oportunidades. Es por esto que los grupos armados organizados han logrado continuar con sus actividades, tanto en la economía formal como en la informal, debido al dinero lavado en lugares con tradición más laxa en torno a las regulaciones y a los paraísos fiscales.

El incremento en el lavado de activos ha permitido que diversos actores tanto legales como ilegales se beneficien de este. Es por esto que derribar al lavado de activos proveniente del crimen es muy difícil, "en cada país está definido de manera específica, así como las medidas tomadas en contra de este son muy diferentes" (Schneider, 2010, 25). De igual manera, Aleksoski (2015) afirma que el crimen organizado en forma de lavado de activos no puede ser eliminado. Es uno de los procesos que involucran varias personas orientadas criminalmente que están incluso apoyadas por las instituciones que controlan la legislación del dinero. Si se usan los mecanismos para luchar en contra de este tipo de crimen, se puede disminuir, pero no pueden eliminarlo.

\subsubsection{Proveniencia del dinero}

Schneider (2010), afirma que la necesidad del lavado de activos es explicada desde casi todas las transacciones ilegales que son hechas con dinero, el monto de dinero de las actividades criminales debe ser lavado con el fin de tener una ganancia "legal" para hacer alguna inversión o para consumir en el mundo legal. Es por esto que este elemento de financiación es muy importante puesto que permite la prevalencia de los diferentes grupos debido a que les da la capacidad de poder adquirir los insumos necesarios para perpetuar sus negocios o para pagar la mermelada necesaria para continuar con estos. 
Es importante tratar de cuantificar y estimar el volumen y el desarrollo de las actividades de lavado de activos, se hace mediante el modelo económico MIMIC ${ }^{4}$, el monto del lavado de activos y las ganancias de las actividades criminales estimadas usadas como variables causales de varios tipos de actividades criminales, el funcionamiento del sistema legal, los ingreso per cápita y de distribución y como indicadores el dinero confiscado, el dinero per cápita y las personas procesadas. La estimación de estos montos es necesaria con el fin de identificar claramente los factores de mayor incidencia en este tipo de actividades ilegales cometidas por los grupos armados organizados (Schneider, 2010, 24).

El lavado de activos ha aumentado desde 1996 de 273 billones a 603 billones de dólares en 2006, por parte de veinte países de la Organización para la Cooperación y el Desarrollo Económico (OCDE). "Del valor de 2006, 338 billones es el estimado del resultado del lavado de activos del negocio de las drogas" (Schneider, 2010, p. 26). Estas cifras estimadas son preocupantes dado la estrecha relación de los grupos armados organizados con el negocio de las drogas o el narcotráfico; si bien Colombia no hace parte de los países que conforman la OCDE, según las estimaciones, muchos de los estados receptores de las drogas traficadas desde aquí conforman la OCDE. Así mismo, es importante hacer hincapié en la relevancia y la magnitud del crimen organizado transnacional, en el que ciertos de los grupos armados organizados pueden encajar como parte de estos.

En cuanto al monto del capital legal que pertenece al sector criminal depende del costo técnico de las operaciones de lavado de activos y de los costos derivados de la regulación antilavado de activos. Barone \& Masciandaro (2010) analizaron los costos de reinvertir el dinero producto del lavado de activos en mercados legales: según las simulaciones, los resultados muestran que el costo de reinvertir cuando las devoluciones ilegales incrementan, cuando compartir los ingresos ilegales para ser lavados decaen, cuando las ganancias ilegales son mayores y cuando el índice de la regulación de lavado de activos es alto.

Barone \& Masciandaro (2010), concluyen que cada mejora en la efectividad de las regulaciones antilavado de activos producirá una disminución en el multiplicador y, consecuentemente, en el valor de la actividad de lavado de activos el cual corresponde a un incremento en todo el bienestar público. El

\footnotetext{
${ }^{4}$ Múltiples indicadores y múltiples causas, este modelo relaciona la extensión no observada de la economía oculta con factores observables, que se suponen alientan o desalientan las actividades en este tipo de economía, y con indicadores observables, que se consideran el alcance de la economía oculta $\operatorname{OECD}(2009,159)$.
} 
modelo que proponen puede ser utilizado para explorar los posibles efectos de regulación en el monto total de los activos legales que es poseído por los grupos de crimen organizado.

Así mismo, entre el 60 y el $80 \%$ de los fondos de drogas son subsecuentemente legalizados mediante el lavado de activos. "Según el modelo y la información, cerca de 53 billones de dólares relacionados con las ganancias de la cocaína pasaron por el lavado de activos en 2009. Montos significativos de las ganancias de la cocaína, es decir, la mitad o 27 billones de dólares, son invertidos respectivamente en las jurisdicciones en donde fueron generados" (Pietschmann \& Walker, 2011, 128). La reinversión del dinero proveniente de las actividades de lavado de activos es un factor muy importante puesto que permite legalizar dicho dinero. En muchas ocasiones, este tipo de dinero se utiliza para la creación de empresas o fachadas legales mediante las cuales se legitiman los activos relacionados a las empresas.

"Hay una tendencia significativa a ser reinvertidos los fondos ilícitos en las operaciones de tráfico de drogas, lo cual tiene implicaciones negativas para la sociedad a largo plazo" (Pietschmann \& Walker, 2011, 128). Este fenómeno se presenta frecuentemente en Colombia, especialmente en los territorios controlados por estos grupos criminales, la sociedad se ha venido acostumbrado a la inyección de capital a través de empresas ilegales.

\subsection{Empresa ilegal}

\subsubsection{Actividades criminales}

Kaplan \& Matteis (1968), afirman que después de apostar, el préstamo ilegal de dinero es la segunda fuente de ingresos del crimen organizado. Las ganancias de las apuestas frecuentemente proveen el capital inicial para las operaciones del préstamo de dinero. Por esto, el préstamo ilegal de dinero ha crecido en proporciones tremendas, produciendo millones en ganancias, victimizando a muchas personas y trayendo miedo y violencia a la comunidad. Los negocios de préstamo ilegal de dinero es el paso final en el proceso de generar ingresos a través del crimen y luego buscan inversiones más rentables para esos fondos. Esto elemento de financiación es propio de los grupos delictivos organizados quienes, conforme a van adquiriendo dinero, van prestando a través de intermediarios que sirven de cobradores.

"Mientras que las operaciones tradicionales de crimen organizado como apuestas, narcotráfico y prostitución tienen variedad de grados, riesgos 
significativos de acusación y penas severas, no hay leyes existentes y comprobadas para el préstamo ilegal de dinero" (Kaplan \& Matteis, 1968, p. 248), lo cual fomenta que este tipo de actividad criminal se evidencie en el día a día de las personas quienes, por diferentes razones, no pueden acceder a préstamos por vías legales y se ven en la penosa obligación de acudir a estos grupos.

Existe una relación entre los beneficios de las actividades ilícitas y la influencia en una potencial revolución de las guerrillas; en este sentido, como los beneficios de las actividades ilícitas crecieron, la influencia potencial revolucionará, pero existen menos incentivos para derrocar el orden económico, un cambio que podría deslegitimar las actividades criminales, ilegales o ilícitas. Tomar el poder requiere un cambio en el sistema político. "Un grupo cuyos beneficios son largos bajo el régimen actual pierde los incentivos para crear una revolución política; en este sentido, los objetivos revolucionarios ya no son compatibles con los criminales" (Offstein, 2003, 129). Esto puede ser una razón que explique por qué los grupos armados organizados no buscan cambiar ni el orden político ni el económico -exceptuando el ELN- puesto que, si cambia, podría ir en contra de sus intereses económicos.

Algunos grupos del crimen organizado incluyen en su accionar el uso de tácticas terroristas con el fin de reducir la desobediencia y favorecer el control sobre ciertos territorios considerados estratégicos para el cumplimiento de sus funciones. De igual manera, actualmente se consideran que hay grupos de crimen organizado terroristas.

Es por esto, que es relevante dar cuenta de las principales diferencias de las fuentes de financiación entre el terrorismo y el crimen organizado que están relacionadas con: a) la ideología común y los objetivos indiscriminados, ningún propósito relacionado con las ganancias, los recursos financieros son necesarios para la planeación y ejecución de ataques terroristas, y la autofinanciación es posible mediante actividades criminales, pero también obteniendo recursos legales como donaciones u organizaciones de caridad; y b) el dinero sucio es obtenido a través de varias actividades criminales como tráfico de droga, personas y armas, las cuales son realizadas generalmente por los grupos de crimen organizado y es necesario que realicen operaciones de lavado de activos para poder hacer uso de este, generando así grandes ganancias (Schneider, 2010, 9-13). A pesar de que hay una clara relación en las fuentes de financiación entre el terrorismo y el crimen organizado se debe tener en cuenta el creciente nexo entre el crimen y el terrorismo y su efecto negativo en la economía, así como también en la sociedad. 
Las actividades criminales cometidas por los integrantes delos grupos de crimen organizado son varias. Así como las figuras Heidao en Taiwán hacen dinero a través de una variedad de actividades criminales porque los hermanos mayores son obligados a apoyar a sus seguidores financieramente, ellos siempre están bajo la presión de hacer dinero y ser generosos con sus hermanitos. "Por esto, los líderes Heidao generalmente están involucrado en actividades como extorsión, apuestas, manejar los establecimientos comerciales de sexo, recolectar deudas de los prestamistas del mundo clandestino y resolver disputas comerciales. No importa qué tipo de actividad generadora de dineros estos persigan, con el fin de conducir sus "negocios" efectivamente, siempre está la necesidad de ellos como una amenaza creíble, pues estarán en la capacidad de actuar si el caso lo requiere" (Chin, 2016, 59).

Lo anterior se puede traducir al fenómeno de los grupos armados organizados en Colombia, dado que varios de estos grupos tienen estructuras "paternalistas", en tanto que aquellos criminales que tienen poder y dinero "financian" a familiares o allegados que tienen intención de ingresar al negocio criminal. Además, las diversas actividades mencionadas con respecto a los Heidao son ejecutadas por los grupos, lo cual evidencia la existencia de generalidades entre actores del crimen organizado.

En este sentido, las actividades de las industrias criminales en México están basadas principalmente en la extorsión a negocios y empresas, tráfico de drogas, narcomenudeo, tráfico de armas, robo y contrabando de combustibles, así como el control de cadenas productivas de varios commodities tales como el acero o el aguacate. De igual forma, el esquema en el que se proporciona la protección a las actividades realizadas por los diferentes operadores de las economías, tanto lícitas como criminales, dentro del territorio bajo su control, les ha permitido expandirse a otras actividades productivas y comerciales diversificadas así las fuentes de ingresos (Cruz, 2016, 113).

Esto puede ejemplificar el comportamiento de los diferentes grupos armados organizados los cuales cuentan con estos patrones de comportamiento en cuanto a las actividades ilícitas.

\subsubsection{Similitud con las empresas legales}

Albanese (2008), afirma que los grupos de crimen organizado operan como empresas legales con los objetivos de sobrevivir y de obtener ganancias, mientras controlan las presiones a las que se enfrentan de los proveedores, consumidores, reguladores y competidores. En cada categoría pueden 
verse los indicadores específicos que pueden desarrollar las medidas de la naturaleza comparativa de proveedores, demanda, competición de otros grupos y productos, y reguladores. Es posible evaluar los riesgos comparativos del crimen organizado involucrado de los diferentes tipos de productos y de mercados ilícitos. Evidencia que, a pesar de ser grupos ilegales, tienen en cierta medida una estructura y un sistema operativo similar a las empresas legales, la diferencia es que la competencia entre estas "empresas" tiene implicaciones sociales muy graves como matanzas y desplazamientos.

Es importante aclarar que el mercado ilegal es reducido, por esto las organizaciones criminales pueden dedicarse a actividades legales con el fin de financiar el crecimiento de sus actividades ilegales. "Entre más grande sea la organización más probabilidad hay de que esta invierta en las actividades legales con el fin de facilitar la continuación de las ganancias y de recibir más ingresos" (Cruz, 2016, 114).

\subsection{Tráfico de personas y migrantes}

El fenómeno migratorio, principalmente desde algunos países de América Latina hacia Estados Unidos, no se ha abordado desde una perspectiva integral, con soluciones razonables para todas las partes y desde sus múltiples facetas y dimensiones; el crimen organizado seguirá teniendo un peso considerable en uno de los fenómenos más relevantes de la región (Solís \& Rojas, 2008). Este tipo de criminalidad ha adquirido, gradualmente, dimensiones transnacionales al conectar sus actividades en regiones fronterizas, extendiéndose a lo largo del mundo, y tener una fuerte vinculación con el fenómeno migratorio, aprovechándose de las diferentes necesidades de los migrantes.

La trata de personas es un delito mundial en el que los hombres, las mujeres y los niños son tratados como productos con fines de explotación sexual o del trabajo. Si bien las cifras varían, según una estimación de la Organización Internacional del Trabajo (OIT) realizada en 2005, el número de víctimas de la trata era de alrededor de 2,4 millones y las ganancias anuales de unos 32.000 millones de dólares. Sin embargo, las estimaciones más recientes y precisas de la OIT sobre las tendencias generales del trabajo forzoso nos inducirían a pensar que el alcance del problema es mucho mayor. En Europa, la trata de mujeres y niños, principalmente con fines de explotación sexual, genera 3.000 millones de dólares por año y conlleva 140.000 víctimas en un momento dado y una corriente anual de 70.000 víctimas (UNODC, 2011). El monto recibido por esto genera un gran atractivo para la perpetuación de este fenómeno. 
Por otro lado, el tráfico ilícito de migrantes es un negocio bien organizado que moviliza a las personas alrededor del mundo por conducto de redes y grupos delictivos y a lo largo de diversas rutas de tráfico. Los grupos delictivos organizados pueden ofrecer a los migrantes un "paquete de viaje" en el que el trato que reciben a lo largo de la ruta corresponde al precio que pagan a los traficantes. En el proceso de tráfico sus derechos suelen ser violados y es posible que los roben, los violen, los secuestren o incluso los dejen morir en algunos casos, cuando los riesgos aumenten demasiado para los traficantes. A muchos de los traficantes no les importa si los migrantes se ahogan en el mar, mueren de deshidratación en el desierto o fallecen sofocados en un contenedor. Ese comercio está avaluado en miles de millones de dólares por año. En 2009, se generaron unos 6.600 millones de dólares de resultas del tráfico ilegal de 3 millones de migrantes de América Latina a América del Norte, en tanto que el año anterior el traslado ilegal de 55.000 migrantes de África a Europa generó 150 millones de dólares (UNODC, 2011). Esta cifra se convierte en un factor atractivo para la realización de este tipo de crimen.

Los grupos de delincuencia organizada se aprovechan de los migrantes que se trasladan hacia el norte, quienes pueden ser muy vulnerables. La reciente crisis económica ha reducido el flujo de migrante objeto de tráfico, pero aquellos que continúan el viaje hacia el norte están sujetos a una serie de abusos, incluyendo ser retenidos por un rescate. Algunos migrantes son explotados sexualmente, en particular al llegar a Guatemala y al sur de México (UNODC, 2012), lo cual genera un ingreso adicional por cada migrante.

\subsubsection{Redes de tráfico}

"El tráfico de personas se ha determinado como un factor complicado debido a la consideración del nivel del involucramiento del crimen organizado en el tráfico de personas, su evolución y diversidad ha facilitado la inmersión de estos grupos en esta forma de tráfico". (Langhorn, 2018, 7)

Aronwitz (citado en Langhorn, 2018), observa que las operaciones de tráfico pueden caer en un continuo rango de los traficantes individuales a través de las redes de tráfico internacional altamente estructuradas, hay sindicatos de tráfico caracterizado por pequeños grupos de criminales organizados quienes pueden involucrarse en tráfico nacional o en el tráfico internacional a pequeña escala. Estas redes criminales son altamente flexibles y pueden estar conformadas por miembros de familia o amigos; dependiendo del nivel del grupo en el que se encuentre se verá reflejados los ingresos. Otro nivel de organización involucra el tamaño medio, grupos más sofisticado los cuales están involucrados en la 
provisión de las víctimas para los mercados sexuales de países extranjeros, venden a sus víctimas a los dueños de los prostíbulos y pueden organizar la rotación de ellas entre ciudades y países.

Las organizaciones altamente establecidas controlan completamente el proceso desde el reclutamiento y transporte hasta la explotación y la eliminación de las víctimas. Estos grupos proveen todos los servicios a través de la cadena tráfico completa, la cual puede también incluir algunos como la falsificación de documentos, casas seguras y el mantenimiento de las relaciones con el gobierno corrupto. Están caracterizadas por ser horizontales y descentralizadas. "Su flexibilidad le permite una respuesta rápida a la aplicación de la ley y a los cambios legislativos y su habilidad de adaptación a los mercados fluctuantes de demanda" (Langhorn, 2018, 8), lo que facilita su transformación y adaptación, reduciendo el margen de acción estatal.

Hay lazos entre el lavado de activos y el tráfico de personas en Australia. Contradice la literatura existente ya que muestra que hay casos aislados donde los sindicatos están involucrados en otros crímenes. Es importante recalcar que el modelo carece de referencia a los indicadores victimológicos. En el paradigma del tráfico de personas las víctimas son un elemento esencial para el éxito de cualquier grupo de crimen organizado. "El estudio ofrece las implicaciones para el cumplimiento de la ley según los resultados; de igual manera, habla sobre el uso que pueden darle las agencias de inteligencia a esta información" (Langhorn, 2018, 20-21). Esta se vuelve relevante en cuanto a los métodos y mecanismos mediante los cuales se contrarresta a estos grupos.

\subsubsection{Rentabilidad}

Gottschalk (2007), sostiene que las organizaciones criminales que están involucradas en el tráfico de personas son típicas cadenas de valor, estas están creadas a través de una producción eficiente de bienes y servicios basados en la variedad de los recursos, por lo que hay similitud en el entendimiento de las organizaciones criminales con las no criminales, debido al funcionamiento de las mismas. Nicola (como se citó en Gottschalk, 2007), afirma que hay al menos tres fases para dividir a las personas: reclutamiento, transferencia y la entrada en un país de destino. El tráfico de personas involucra un paso más: la explotación, el cual puede ser comparado con el mercadeo o con las ventas. De igual manera, generalmente el tráfico de personas va acompañado del tráfico de armas o del narcotráfico, por lo que los grupos de crimen organizado no solo se lucran con el tráfico de personas sino con los otros también debido a que las rutas son similares, como ya se había mencionado anteriormente. 
Sampó (2017), sostiene que la trata de personas es tan rentable debido a que venden a una sola víctima con varios fines. Así mismo, la criminalidad organizada necesita de la complicidad del Estado para blanquear los activos generados en sus actividades ilícitas. La demanda de los servicios (narcotráfico, trata de personas y lavado de activos) es fundamental para el desarrollo de las organizaciones del crimen, se constituyen como un ciclo puesto que si no hay dinero producto de alguna actividad ilegal o ilícita no hay necesidad del lavado de activos.

\subsection{Corrupción}

\subsubsection{Relación con las otras fuentes de financiación}

La corrupción es un fenómeno que está presente en todos los ámbitos e instancias tanto públicas como privadas en el país. La relación con los diferentes elementos de financiación es perjudicial en tanto que facilita la perpetuación, aumento de poder y la supervivencia de estos grupos, lo cual no solo es malo para la economía sino también para la sociedad.

El objetivo de los grupos de crimen organizado es obtener ganancias financieras, tanto como cuenten con un mercado medible para sus servicios, estos sobrevivirán a ellos. Sellin (1963), afirma que se encuentran atrapados en un dilema conforme a las circunstancias, aportando las propias normas, basados en la noble esperanza de que las normas rescatarán a los ciudadanos de sus propios malvados apetitos o los protegerán en contra de la explotación; esto ha ayudado inadvertidamente a crear una fuente arraigada de soborno y corrupción política e indeseables efectos en la mentalidad de las personas del común. La corrupción por parte de estos grupos es muy evidente, hasta el punto de haberla normalizado en el sentido en que si hay una gran magnitud de actividades ilícitas hay una alta tasa de corrupción.

A su vez, el Estado y la economía fallida proveen elementos esenciales para que el crimen organizado infeste la sociedad. Una judicatura corrupta priva a la nación de una defensa efectiva contra el crimen organizado y una activa economía clandestina que provee a los sindicatos criminales con amplias oportunidades de expandir su influencia y legitimidad entre los ciudadanos ordinarios. Sin embargo, "negar libertades políticas y una tasa alta de desempleo no son contribuyentes para las actividades criminales como se esperaba al principio" (Sung, 2004, 125).

La acumulación de riqueza en la sociedad, especialmente cuando se produce de manera rápida y sin una explicación coherente, también está sospechosamente 
ligada al crimen organizado. "Todo aquel que se hace rico de la noche a la mañana," manifestó un entrevistado, "será un mafioso a los ojos de la opinión pública." Y esto también tiene un impacto en los jóvenes pues podría llegar a incitarlos al crimen organizado. "Ya nadie quiere trabajar esforzándose mucho", exclamó una persona. "Una pistola, un teléfono celular y un maletín ejecutivo parecieran ser requisitos indispensables para hacerse rico" (Solís \& Rojas, 2008). Se crea una relación estrecha y, en cierta medida aceptada por la sociedad, entre el crimen y la riqueza.

El financiamiento de los partidos políticos, en especial durante las campañas electorales, se transforma en un punto crucial sobre el cual puede incidir el crimen organizado, generando graves daños a la democracia. En la actualidad es posible afirmar que, de una u otra manera, con variaciones en su intensidad, este tipo de criminalidad ha penetrado una parte significativa de nuestros sistemas políticos o ha buscado entresijos durante las campañas electorales para introducir dinero y lograr influencia (Solís \& Rojas, 2008). Así mismo, es difícil distinguir entre la corrupción sistémica de gran envergadura y el accionar del crimen organizado, en particular el referido al lavado de dinero. Los efectos negativos se expresan en diversos campos, donde la falta de transparencia y la corrupción dificultan la inversión, afectan el derecho de propiedad, distorsionan la competencia, erosionan las instituciones y diluyen los incentivos legítimos para el desarrollo económico y, en general, para la evolución y consolidación del Estado (Solís \& Rojas, 2008).

Wright (2006) sostiene que el hecho del involucramiento de Estados y corporaciones legítimas en "negocios sucios" demuestra una necesidad de regulación del mundo financiero. Así mismo, Barone \& Masciandaro (2010), afirman que gracias al lavado de activos los criminales están en la capacidad no solo de consumir y gastar sino de invertir capital en circuitos legales e ilegales de la economía, la gran mayoría de estas inversiones son exitosas y rentables, las organizaciones criminales crecen en fuerza, aumentando el nivel de la corrupción criminal en toda la economía. Lo cual les permite un margen de maniobra mucho mayor en torno a las diferentes actividades criminales.

En este sentido, el narcotráfico, como parte de la delincuencia organizada transnacional, corrompió al sistema de justicia y seguridad; esto suscitó que se descuidaran otras clases de crímenes, los que obviamente aumentaron. Así mismo, la delincuencia organizada y las prácticas corruptas van de la mano: la corrupción facilita las actividades ilícitas y las intervenciones de los organismos encargados de hacer cumplir la ley. La lucha contra la corrupción es, por tanto, esencial para combatir la delincuencia organizada (Vásquez, 2013). Es más, se 
ha establecido un nexo entre esta última, la corrupción y el terrorismo, puesto que en ciertos casos el uso de actos terroristas favorece a algunos intereses de los diferentes agentes públicos.

La corrupción, amparada en los altos niveles de impunidad y en la incapacidad del Estado de sostener el imperio de la ley, logra que funcione el andamiaje necesario para que las organizaciones criminales se asienten y desarrollen sus negocios. La corrupción se manifiesta de manera tal que se convierte en la base que sostiene el actuar de las organizaciones criminales, siendo asimismo el Estado cómplice de las actividades ilícitas (Sampo, 2017). Algunos sugieren que los lazos sospechosos entre los partidos políticos y algunas corrientes ilegales y esquemas oscuros de financiamiento, incluyendo a grupos dedicados al crimen organizado, influyen negativamente en la manera en que la ciudadanía valora la representatividad política.

En cuanto a los estudios, Langhorn (2018) utiliza metodológicamente el Sleipnir wightings, el cual evidenció que el atributo más valorado por un sindicado de crimen organizado fue la corrupción; los resultados del estudio demostraron que eran muy pocas las instancias de la actividad de corrupción observable de los sindicatos criminales que fueron estudiados.

A pesar de eso, lo que es evidente es que esos sindicatos que tuvieron atributos observables de corrupción fueron calificados más altos, como una amenaza, que aquellos que no, puesto que si la corrupción es observable los niveles de la misma han sido desproporcionales, esto da a entender la relevancia de los elementos de financiación debido a que lo recursos económicos son considerablemente altos para poder sostener dichos niveles de corrupción (Langhorn, 2018, 12).

En este sentido, se ha evidenciado que un líder de las AUC en Urabá controlaba miles de elecciones de las Juntas de Acción Comunal; estas se convierten en los que hacían la encubierta del control paramilitar en las ciudades de las juntas. "De igual manera, lograron permear el Congreso en 2002 al conseguir dos asientos; crearon una ONG llamada Asociación Comunitaria de Córdoba y Urabá con el fin de promover el desarrollo sostenible, buscó financiación de gobiernos regionales, del nacional y de la comunidad internacional" (BojicicDzelilovic, Kostovicova, Escobar, \& Bjelica, 2015, 1894).

Gracias al elaborado sistema de relaciones con varios actores alrededor de la industria del aceite de palma de Urabá y los actores estatales, entre los diferentes niveles de gobierno, las AUC ganaron accesos a un fondo significativo 
del gobierno nacional y de la comunidad internacional lo que generó que se involucraran en actividades legales rentables, disminuyendo así la capacidad de consolidación estatal en estas zonas" (Bojicic-Dzelilovic, Kostovicova, Escobar, \& Bjelica, 2015, 1895).

Lo anterior, refleja que la financiación de estos grupos también se puede presentar por medios "legales" en tanto que conforman organizaciones no gubernamentales con supuestos fines sociales, pero resultan ser una fachada que incluso sirve para lavar activos.

"Las bandas criminales cuentan con una red amplia de protección entre las fuerzas de seguridad y, a su vez, cuentan con los recursos suficientes para corromper el sistema judicial" (Cruz, 2016, p. 119). En este sentido, "la corrupción por parte del crimen organizado es muy grande, es un activo difícil de igualar ya que consigue toda la impunidad que sea necesaria para que su negocio prospere, debido a su dinero o la información que posee, con la que se intimida a los funcionarios, produciendo un mayor margen de maniobra para los grupos al margen de la ley" (Sampó, 2017, 275).

Este fenómeno ha permitido la perpetuación de las actividades ilegales en las que están involucrados los grupos armados organizados y los grupos delincuenciales organizados, lo cual tiene repercusiones muy negativas no solo para la sociedad sino para la consolidación del Estado. En este sentido, la debilidad estatal tras la penetración de estos grupos en los diferentes entes ha conllevado a conformación de un ciclo vicioso en el que, si hay recursos para corromper a los funcionarios, hay actividades ilegales, hay ganancias y empieza de nuevo.

\subsection{Otros}

\subsubsection{Minería ilegal}

La minería, como actividad ilegal, tiene un trasfondo dentro de la realidad económica: el dinero y la acumulación del mismo y, por ende, la necesidad de estos grupos de cualificar y mejorar técnicas delictivas que les permitan no solo obtener dinero, sino introducirlo en el mercado legal, teniendo en cuenta que dentro de los estímulos que contribuyen al fortalecimiento de la actividad ilegal y criminal se encuentran: el aumento de la demanda de los minerales preciosos, los problemas de información, la carencia de ordenamiento territorial, un sistema legal ambiguo, altos costos y requisitos de entrada a la formalidad, maximización de ganancias con bajos costos de 
operación e informalidad en los mismos lugares en donde existe la mayor producción legal de oro (Maldonado \& Rozo, 2014).

Si se comparan variables de la minería aurífera criminal e ilegal con las del fenómeno del narcotráfico, se observa que son actividades distintas, en donde el desarrollo de la minería criminal resulta más eficaz. Esto obedece a que el tiempo empleado en la obtención del mineral y los costos de producción son menores, el producto resultado de la explotación es ilegal y los controles en la distribución y comercialización del mineral aún son laxos (Maldonado \& Rozo, 2014). La facilidad de la obtención de beneficios genera que este tipo de negocios sea más atractivo.

Ha habido un auge en la explotación de oro en Quibdó a partir del 2012, esto, a su vez, está relacionado con el incremento de las tasas de homicidios, "es claro que las agrupaciones criminales utilizan diferentes actividades para financiar su accionar, por lo que además del oro también inciden en el narcotráfico, explotación de madera, extorsiones a los comerciantes, expendios de droga, el manejo del pago diario entre otras" (Escobedo \& Guío, 2017, 56). El incremento de las tasas de homicidio se puede relacionar con el aumento de la incidencia en torno a diferentes actividades ilícitas por parte de los grupos armados organizados. De igual forma, se evidencia que un elemento de financiación como la minería ilegal generalmente está acompañado de los otros junto con otras actividades ilegales.

El casco urbano de Quibdó se convirtió en un centro de compra de oro muy importante, además de un espacio en donde se manejan las finanzas de las exploraciones, se suministra la logística de las mismas y se lava el dinero del narcotráfico, así como la organización del tráfico de influencias y de la corrupción. "Controlar este lugar en términos criminales implica acceder a una parte de las ganancias del oro, por lo que es la razón principal de las disputas" (Escobedo \& Guío, 2017, 56) La incidencia de los grupos armados organizados en los diferentes aspectos de la vida de la comunidad es negativa, no solo porque se fomentan las actividades criminales sino por la misma corrupción que se produce y mantiene con la instalación y toma de control por parte de estos grupos.

\subsubsection{Tráfico de especies naturales}

El tráfico ilegal de especies animales y vegetales es muy atractivo para el crimen organizado. Entre otras razones, esto se explica por el excelente mercado que representa. La situación en este ámbito es tan grave que los científicos calculan 
que, de continuar sin controlarse, la acción de bandas criminales organizadas que trafican con especies naturales podría contribuir decisivamente a su exterminio. El Programa de las Naciones Unidas para el Medio Ambiente (PNUMA) estima que hasta un 2,5\% de todas las especies del bosque tropical húmedo podrían desaparecer hacia el 2020 (Solís \& Rojas, 2008). Es por esto que se ha fomentado la regulación y el control de este tipo de tráfico con el fin de hacer menos rentable este negocio.

El comercio ilegal de flora y fauna silvestres es otro negocio lucrativo para los grupos delictivos organizados, en el que los cazadores furtivos consiguen pieles y partes del cuerpo de los animales para exportar a mercados extranjeros. El tráfico de marfil, cuernos de rinocerontes y pieles y huesos de tigres de África y el Asia suroriental a Asia produce 75 millones de dólares por año de ganancias mal habidas y pone en peligro la existencia de algunas especies. Los grupos delictivos organizados también comercian plantas raras y animales vivos, amenazando su propia existencia para atender a la demanda de coleccionistas o consumidores desprevenidos. Según el Fondo Mundial para la Naturaleza (WWF), los traficantes trasladan ilegalmente más de 100 millones de toneladas de pescado, 1,5 millones de pájaros vivos y 440.000 toneladas de plantas medicinales por año (UNODC, 2011), causando graves daños al ambiente y siendo muy rentables para estos grupos encargados del traslado.

Abarca el contrabando de materias primas, entre ellas diamantes y metales raros, con frecuencia desde zonas de conflicto. Mientras tanto, el tráfico ilícito de madera en el Asia suroriental genera ingresos anuales por valor de 3.500 millones de dólares. Además de financiar grupos delictivos, esa clase de actividad clandestina, en última instancia, contribuye a la deforestación, el cambio climático y la pobreza rural (UNODC, 2011). En este sentido, genera gran dificultad para la consolidación estatal ya que dichas actividades son muy rentables y generalmente están acompañadas de la corrupción de los funcionarios.

Viollaz, Graham, \& Latsman (2018), estiman que en el ambiente criminal incluyen el tráfico de animales en las cinco actividades criminales más lucrativas del crimen transnacional organizado con ganancias de 91.258 millones de dólares anualmente, un incremento del $26 \%$ en ganancias desde el 2014 que fue la última vez que se estimó. A su vez, varias investigaciones han demostrado que los traficantes frecuentemente usan las mismas rutas de tráfico de animales para otros commodities ilegales como armas de fuego, personas y drogas. "También pueden usar formas similares de manejar las ganancias del tráfico de animales como del narcotráfico" (Viollaz, Graham, \& 
Lantsman, 2018). El lavado de activos es la forma más común de manejar las ganancias producidas por el narcotráfico, así como por el tráfico de animales. De igual manera, los crímenes financieros son parte de cada parte del proceso de tráfico de animales sin importar el actor. Estos crímenes incluyen robo, fraude, soborno, corrupción, cibercrímenes y evasión de impuestos.

\subsubsection{Tráfico de armas}

América Latina es una región que se concibe estratégica para el control del tráfico de armas y otras formas de crimen organizado, específicamente por su historia reciente de conflictos armados, por ser zona de tránsito de diversos tipos de contrabando, por sus altos niveles de desigualdad social y por poseer una institucionalidad débil que plantea incertidumbre en torno al cumplimiento de la ley y la realización de procesos judiciales transparentes y oportunos (Solís \& Rojas, 2008). Esto permite que las actividades ilegales sean más atractivas no solo por su rentabilidad sino por los niveles de impunidad.

El tráfico ilícito de armas de fuego genera de 170 a 320 millones de dólares por año y pone en manos de delincuentes y pandillas armas cortas y rifles de asalto. Es difícil calcular el número de personas que caen víctimas de esas armas ilícitas; no obstante, en algunas regiones, por ejemplo en América, existe una firme correlación entre los índices de homicidios y el porcentaje de homicidios perpetrados con armas de fuego, lo que en cierta medida da cuenta de la relación entre tráfico de armas y grupos armados organizados (UNODC, 2011).

De la misma manera, hacen uso de los servicios de internet y otras tecnologías como el GPS para localizar envíos (de armas o dinero) en zonas alejadas o para concretar reuniones en "estados fallidos" o parajes inhóspitos del primer mundo, algunas de estas acciones son catalogadas como ciberdelitos. Estos mecanismos facilitan la práctica de un "crimen transnacional" con capacidad para permear las fronteras convencionales, y ejecutar atentados, lo que se debe al fácil acceso a internet y, en general, a las tecnologías de la información (Cabarcas, 2011).

Los grupos de delincuencia organizada también pueden dedicarse al tráfico de armas de fuego tanto robadas como compradas a oficiales corruptos. Las armas militares son traficadas tanto en dirección norte como sur. En muchos aspectos, los grupos territoriales actúan como un Estado dentro del Estado, y pueden trasladarse fácilmente a otras formas de criminalidad si su actual cartera de actividades da pruebas de no ser rentable (UNODC, 2012). Esto dificulta el accionar estatal para contrarrestar el accionar de dichos grupos. 


\section{Vacíos o necesidades de los elementos de financiación de los GAO y GDO}

\subsection{Narcotráfico}

En relación con los vacíos, si bien los autores describen el fenómeno del narcotráfico y explican su relevancia, no ahondan en la explicación del ¿por qué? y del ¿cómo? Este elemento de financiación permite la perpetuación de los grupos que se financian mediante el narcotráfico, el artículo de Sousa se centra casi exclusivamente en dar a entender las relaciones sociales al interior del crimen organizado y cómo el uso de la economía criminal es una forma de supervivencia.

También se evidencio un vacío en el artículo de Bojicic-Dzelilovic et al., en cuanto a la explicación relación existente entre las actividades de sustitución en los territorios más golpeados por el conflicto, el narcotráfico y la corrupción como elementos fundamentales para las autodefensas que pasan a ser grupos armados organizados.

\subsection{Lavado de activos}

Como necesidad se encuentra, tras la revisión de las diferentes fuentes, la necesidad de ahondar en las repercusiones de los ingresos del narcotráfico como fuente principal del lavado de activos en la perpetuación de los grupos armados organizados y de los grupos delictivos organizados. De igual manera, el modelo utilizado por Barone \& Masciandaro es muy bueno puesto que a partir de este se pueden estimar las mejoras en el costo de las regulaciones a las actividades criminales, con el fin de hacerlas menos atractivas y rentables. Finalmente, es menester que se desarrolle más la relación del lavado de activos como una forma en sí misma de crimen organizado con las repercusiones de esta actividad en la economía de los grupos y en la legal.

\subsection{Empresa ilegal}

Se detectan vacíos en el sentido de que no se observa, por ejemplo en el libro de Sellin, la relación real entre los negocios, mercados o empresas ilegales con la continuidad en el mundo criminal por parte de los grupos de crimen organizado. No explica bien cómo se logran las ganancias financieras y por qué estas ganancias son indispensables para la supervivencia de los grupos. Además, el seguimiento a lo propuesto por el autor es nulo, según el presente estado del arte. 
En cuanto al negocio del préstamo de dinero ilegal no se ahonda en cómo este tipo de préstamos es una forma en sí de lavado de activos y de qué manera permite la continua financiación y el mantenimiento de los grupos armados organizados. Offestein no desarrolla la relación entre las diferentes acciones criminales y la supervivencia del grupo, como factores determinantes para el cumplimiento de su objetivo principal.

Albanese da cuenta de los riesgos del involucramiento en los diferentes productos y mercados ilegales, pero no se realiza un análisis del impacto que tienen dichos productos y mercados como elementos claves en la financiación y preservación del poder de los grupos de crimen organizado.

En el artículo de Cruz falta desarrollar y describir las implicaciones de las actividades ilícitas y criminales que son ejecutadas por los subgrupos de los grandes grupos de crimen organizados, como un elemento clave de financiación de los mismos.

En términos de necesidades, se requiere la definición clara de mercado, economías y empresas ilegales, puesto que en los diferentes artículos las mencionaban indiscriminadamente y es menester resaltar la importancia de la diferenciación entre estas.

\subsection{Tráfico de personas}

Se perciben vacíos a la hora de ahondar en las implicaciones sociales, así como en los diferentes elementos que facilitan este tipo de actividad y al momento de dar cuenta de la relación existente con la perpetuación de estos grupos, dado que es muy rentable. Además, no se desarrolla la proporción de las ganancias que se reciben directamente de esta actividad.

\subsection{Otros}

Como vacíos se percibe que no se ha investigado lo suficiente en torno al fenómeno de la minería ilegal, como elemento clave de financiación de los grupos armados organizados y de los grupos delincuenciales organizados. De igual manera, no se desarrollan a profundidad las implicaciones de los crímenes financieros, el tráfico de animales y la extorsión con la continuidad de las actividades ilícitas, el lavado de activos y la supervivencia por parte de los grupos de crimen organizado. 


\section{Conclusiones}

La mayoría de los delitos abarcados en el concepto de delincuencia organizada tienen en común la obtención de rentabilidad en términos económicos al margen de la ley (narcotráfico, lavado de dinero, tráfico de armas, de indocumentados, de órganos, de menores, de vehículos, secuestro, etc.), con excepción del terrorismo, que suele tener un origen y objetivos político.

Todas las organizaciones dedicadas al crimen organizado tienen como patrón financiero el contrabando, partiendo desde ahí realizan más de una actividad principal. De igual forma, cada elemento hace parte de una red, lo que permite la interrelación entre los mismos y, en cierta medida, la dependencia entre estos.

La necesidad de convergencia en las actividades de lavado de activos los cuales les permiten capacidad adquisitiva en cuento a la compra de armas, perpetuación de los diferentes tráficos ilegales, esto facilita su accionar. Por lo tanto, se puede afirmar que son indispensables para la supervivencia, crecimiento y continuación de los grupos organizados al margen de la ley. Lo anterior, permite la generación de políticas y acciones que tengan como propósito mitigar y reducir la participación de estos grupos en dichas actividades ilegales de financiamiento. 


\section{Referencias}

1. Maldonado Sarmiento, I. E., \& Rozo Gutiérrez, L. M. (2014). Convergencia de los grupos armados organizados al margen de la ley en la minería aurífera aluvial en la subregión del Bajo Cauca antioqueño. Criminalidad, 119 - 138. Recuperado de: https://dialnet.unirioja. es/descarga/articulo/5125446.pdf

2. Albanese, J. (2008). Risk Assessment in Organized Crime Developing a Market and Product-Based Model to Determine Threat Levels. Journal of Contemporary Criminal Justice, 263-273. Recuperado de: https://www.researchgate.net/publication/249713873_ Risk_Assessment_in_Organized_CrimeDeveloping_a_Market_and_Product-Based_ Model_to_Determine_Threat_Levels

3. Aleksoski, S. (2015). Money Laudering as a type of organized crime. Journal of Process Management - New Technologies, International, 44- 53. Recuperado de: https://scindeksclanci.ceon.rs/data/pdf/2334-735X/2015/2334-735X1503044A.pdf

4. Barone, R., \& Masciandro, D. (2010). Organized crime, money laundering and legal economy: theory and simulations. European Journal of Law and Economics, 115-142. Recuperado de: https://ideas.repec.org/a/kap/ejlwec/v32y2011i1p115-142.html

5. Barone, R., Side, D. D., \& Masciandaro, y. D. (2018). Drug trafficking, money laundering and the business cycle: Does secular stagnation include crime? Metroeconomica, 409426. Recuperado de: https://onlinelibrary.wiley.com/doi/abs/10.1111/meca.12193

6. Bartolomé, M. (2006). Situacion del Crimen Oganizado en America Latina. Ágora Internacional, 16-20. Recuperado de: https://www.academia.edu/2919288/_2009_ Situaci\%C3\%B3n_del_Crimen_Organizado_en_Am\%C3\%A9rica_Latina

7. Betancourt, L. F. (2014). Cooperación policial entre Colombia y Centroamérica y el Caribe: El Crimen Organizado y el accionar de Ameripol bajo el enfoque multidimensional de la Seguridad Hemisférica. Historia y Arqueología desde el Caribe colombiano. Recuperado de: www.scielo.org.co/scielo.php?script=sci_abstract\&pid...88862014000200011

8. Bojicic-Dzelilovic, V., Kostovicova, D., Escobar, M., \& Bjelica, y. J. (2015). Organised crime and international aid subversion: evidence from Colombia and Afghanistan. Third World Quarterly, 1887-1905. Recuperado de: https://www.tandfonline.com/doi/abs/10.1080/0 1436597.2015.1070664

9. Cabarcas, F. S. (2011). Evolución del régimen de control y financiación del terrorismo. Relaciones Internacionales, Estrategia y Seguridad, 21-34. Recuperado de: http://www. scielo.org.co/scielo.php?script=sci_abstract\&pid=S1909-30632011000200002\&lng=en \&nrm=iso\&tlng=pt

10. Chin, K.-L. (2015). Criminal Activities. En K.-L. Chin, Heijin Organized Crime, Business, and Politics in Taiwan (págs. 46-62). London: Routledge. Recuperado de: https://books. google.co.ke/books?id=92OlDAAAQBAJ\&printsec=frontcover\&source=gbs_book_ other_versions_r\&cad $=4 \# \mathrm{~V}=$ onepage $\& \mathrm{q} \& \mathrm{f}=$ false

11. Clavería, J. R. (2011). El Crimen Organizado. Instituto de Estudio en Seguridad, 1-26. Recuperado de: https://www.galileo.edu/ies/files/2011/04/EL_CRIMEN_ORGANIZADOIES.pdf

12. Cruz, D. S. (2016). Franquicias para el Delito. Nueva Sociedad, 107- 119. Recuperado de: https://www.dinero.com/edicion-impresa/sectores/articulo/como-es-el-negocio-de-lasfranquicias-en-colombia/241046 
13. Escobedo, R., \& Guío, y. N. (2015). Oro, crimen organizado y guerrillas en Quibdó. Fundación Ideas para la Paz, 1-57. Recuperado de: http://cdn.ideaspaz.org/media/ website/document/55b94e00763eb.pdf

14. Giraldo Paredes, H., Ocampo España, J. F., Tuta Niño, F. A., Gallego Ortiz, M., \& López Flórez, Y. (2015). ¿Por qué las personas ingresan a la delincuencia organizada? Análisis del fenómeno en Santiago de Cali. Criminalidad, 103-119. Recuperado de: http://www.scielo. org.co/scielo.php?script=sci_arttext\&pid=S1794-31082015000100008

15. Gottschalk, P. (2007). Managing criminal organisations. International Journal of Police Science \& Management , 289-301. Recuperado de: https://scholar.google.com.co/sc holar? q=Gottschalk,+P.+(2007).+Managing+criminal+organisations.+International +Journal+of+Police+Science+\%26+Management+,+289-301\&hl=es\&as_sdt=0\&as_ vis $=1 \&$ oi $=$ scholart

16. Haman, J. E. (2008). Redes criminales transnacionales: Principal amenaza para la seguridad internacional en la posguerra fría. Criminalidad, 371 - 384. Recuperado de: http://www. scielo.org.co/scielo.php?pid=S1794-31082008000100012\&script=sci_abstract\&tlng=es

17. Holmes, S., \& Kent, y. P. (1991). An empirical analysis of the financial structure of the small and large australian manufacturing enterprises. Journal of Small Business Finance, 141-154. Recuperado de: https://pdfs.semanticscholar. org/2c05/8c06ece37b48547a0e8736880decc9b228a2.pdf

18. J, J. S. (2015). Crimen Organizado: Una aproximación al fenómeno . Gaceta Internacional de Ciencias Forenses. Recuperado de: https://www.uv.es/gicf/4A3_Jimenez_GICF_14. pdf

19. Kleemans, E. (2012). Organized crime and the visible hand: A theoretical critique on the economic analysis of organized crime. Criminology \&Criminal Justice, 615-629. Recuperado de: https://journals.sagepub.com/doi/ abs/10.1177/1748895812465296?journalCode=crjb

20. Langhorn, M. (2018). Human Trafficking and Sexual Servitude: Organised Crime's Involvement in Australia. Salus Journal, 1-25. Recuperado de: http://www.salusjournal. com/wp-content/uploads/sites/29/2018/03/Langhorn_Salus_Journal_Volume_6_ Number_1_2018_pp_1-25.pdf

21. Offstein, N. (2003). An Historical Review and Analysis of Colombian Guerrilla Movements: FARC, ELN and EPL. Desarrollo y Sociedad, 99- 142. Recuperado de: https://revistas. uniandes.edu.co/doi/abs/10.13043/dys.52.4

22. Pietschmann, T. (2011). Estimating illicit financial flow resulting from durg trafficking and other transnational organized crimes. United Nations Office on Drugs and Crime, 3- 138. Recuperado de: https://www.unodc.org/documents/data-and-analysis/Studies/ Illicit-financial-flows_31Aug11.pdf

23. Ponsaers, P. (2008). Does the informal economy link to organised crime? . International Journal of Social Economics, 644-650. Recuperado de: https:/www.researchgate.net/ publication/23648956_Does_the_informal_economy_link_to_organised_crime

24. Prieto, C. A. (2013). Las Bacrim y el crimen organizado en Colombia. FES SEGURIDAD. Recuperado de: https://library.fes.de/pdf-files/bueros/la-seguridad/09714.pdf

25. Rojas, F. (2002). El terrorismo global y América Latina. Revistas Usal. España. Recuperado de: http://revistas.usal.es/index.php/1130-2887/article/view/2367. Recuperado de: http://www.congreso.gob.pe/carpetatematica/2018/carpeta_035/bibliografia/

26. Sampieri, R. H. (2014). Metodología de la investigación. Ciudad de Mexico: McGraw Hill. Recuperado de: https://www.esup.edu.pe/descargas/dep_investigacion/Metodologia\%20 de\%20la\%20investigaci\%C3\%B3n\%205ta\%20Edici\%C3\%B3n.pdf 
27. Sampo, C. (2017). Narcotráfico y Trata de personas, una muestra de cómo el crimen organizado avaza en Argentina. Revista de Relaciones Internacionales, Estrategias y Seguridad, 267-286. Recuperado de: https://revistas.unimilitar.edu.co/index.php/ries/ article/view/2774

28. Savona, E., \& De Feo, M. (1997). International Money Laundering Trends and Prevention/ Control Policies. En E. Savona, \& y. D. M.A, Responding to Money Laundering: International Perspectives (págs. 23-25). Amsterdam: Harwood Academic Publishers. Recuperado de: https://www.researchgate.net/publication/280198807_International_ anti-money_laundering_programs

29. Schneider, F. (2010). Money Laundering and Financial Means of Organized Crime: Some Preliminary Empirical Findings. Economics of Security , 1-29. Recuperado de: https:// www.uibk.ac.at/economics/bbl/bblpapierews0708/schneider.pdf

30. Schneider, F. (2010). The (Hidden) Financial Flows of Terrorist and Organized Crime Organizations: A Literature Review and Some Preliminary Empirical Results. Forschungsinstiut zur Zukunft der Arbeit Institute for the Study of Labor, 1-42. Recuperado de: https://ideas.repec.org/p/iza/izadps/dp4860.html

31. Sellin, T. (1963). Combating Organized Crime. The Annals of the American Academy of Political and Social Science, 12-19. Recuperado de: https://journals.sagepub.com/doi/ pdf/10.1177/000271626334700102

32. Solis, L. G., \& Rojas Aravena, F. (2008). Crimen Organizado en America Latina y el Caribe. Santiago de Chile: FLACSO. Recuperado de: https://biblio.flacsoandes.edu.ec/catalog/ resGet.php?resId $=42584$

33. Sousa, R. S. (2004). Narcotráfico y economía ilícita: las redes del crimen organizado en Río de Janeiro. Revista Mexicana de Sociología, 141-192. Recuperado de: http://www. ejournal.unam.mx/rms/2004-1/RMS04105.pdf

34. Sung, H. E. (2004). State failure, economic failure, and predatory organized: a comparative analysis. Journal of Research in crime and delinquency, 111-129. Recuperado de: https:// journals.sagepub.com/doi/abs/10.1177/0022427803257253

35. Torrijos, V. (2010). Terrorismo Desmitificado verdades y mentiras sobre la violencia en Colombia. Relaciones Internacionales, estrategia y seguridad, 119 - 134. Recuperado de: https://revistas.unimilitar.edu.co/index.php/ries/article/view/135

36. UNODC (2012). Estudios sobre tendencias economicas de la delincuencia organizada. Recuperado de Procuraduria: https://www.procuraduria.gov.co/portal/media/ file/4\%281\%29.pdf

37. UNODC (2011). Delincuencia organizada transnacional - La economía ilegal mundializada. Recuperado de Oficina de las Naciones Unidas contra la Droga y el Delito: https://www. unodc.org/documents/mexico/TOC12_fs_general_ES_HIRES.pdf

38. UNODC (Septiembre de 2012). Delincuencia Organizada trasnacional en Centroamerica y el Caribe Una Evaluación de las Amenazas. Recuperado de Oficina de las Naciones Unidas: https://www.unodc.org/documents/data-and-analysis/Studies/TOC_Central_America_ and_the_Caribbean_spanish.pdf

39. Vásquez, H. T. (2013). La delincuencia organizada transnacional en Colombia. Díkaion, 109-130. Recuperado de: http://www.scielo.org.co/pdf/dika/v22n1/v22n1a05.pdf

40. Vibes, P. (2001). Transnational Organized Crime and Terrorism. Journal of Contemporary Criminal Justice, 243-258. Recuperado de: https://dergipark.org.tr/download/articlefile/155620 
41. Viollaz, J., Graham, J., \& Lantsman, y. L. (2018). Using script analysis to understand the financial crimes involved in wildlife trafficking. Crime, Law and Social Change, 1-20. Recuperado de: https://www.researchgate.net/publication/322728985_Using_script_ analysis_to_understand_the_financial_crimes_involved_in_wildlife_trafficking

42. Wright, A. (2006). Dirty Buysiness: the political economy of organised crime. En A. Wright, Organised Crime (págs. 48-73). Cullompton: William Publishing. Recuperado de: https://journals.sagepub.com/doi/abs/10.1177/17488958080080030702

43. Zúñiga, V. T. (2016). Narcotrafico y el desfio a la seguridad en la triple frontera andina. Relaciones Internacionales, estrategia y seguridad, 103-130. Recuperado de: https:// www.academia.edu/30916916/NARCOTR\%C3\%81FICO_Y_EL_DESAF\%C3\%8DO_A_LA_ SEGURIDAD_EN_LA_TRIPLE_FRONTERA_ANDINA 